\title{
Peripheral Neuropathy and Vasculopathy; Frequency and Associated Risk Factors in Newly Diagnosed Treatment Naive Type 2 Diabetes
}

\author{
Iftikhar Haider Naqvi1 ${ }^{*}$, Abu Talib1, Syed Tahseen Akhter ${ }^{1}$, Syeda Rida Abdi1, \\ Saiyeda Nayema Zehra Rizvi ${ }^{2}$, Muhammad Ubaid ${ }^{3}$ \\ ${ }^{1}$ Department of Medicine Dow University of Health Sciences, Karachi, Sindh, Pakistan \\ ${ }^{2}$ Florence Medical Centre, Karachi, Pakistan \\ ${ }^{3}$ Civil Hospital Karachi, Karachi, Pakistan \\ Email: ^drihnaqvi@gmail.com
}

How to cite this paper: Naqvi, I.H., Talib, A., Akhter, S.T., Abdi, S.R., Rizvi, S.N.Z. and Ubaid, M. (2018) Peripheral Neuropathy and Vasculopathy; Frequency and Associated Risk Factors in Newly Diagnosed Treatment Naive Type 2 Diabetes. Open Journal of Endocrine and Metabolic Diseases, 8, 125-136.

https://doi.org/10.4236/ojemd.2018.85013

Received: April 2, 2018

Accepted: May 26, 2018

Published: May 29, 2018

Copyright $\odot 2018$ by authors and Scientific Research Publishing Inc. This work is licensed under the Creative Commons Attribution International License (CC BY 4.0).

http://creativecommons.org/licenses/by/4.0/

\begin{abstract}
Background: The prevalence of diabetes in Pakistan is $11.45 \%$. The reported prevalence of diabetic foot ulceration in Pakistan is between $4 \%$ and $10 \%$, with the amputation rate of $8 \%-21 \%$. Peripheral neuropathy and vasculopathy are main underlying cause of diabetic foot ulcers. Methodology: It was a cross-sectional non-interventional cohort study where all newly diagnosed treatment naïve type 2 diabetic patients were enrolled. Peripheral neuropathy and vasculopathy were detected by Michigan neuropathy screening instrument (MNSI) and ankle brachial index (ABI) respectively. Risk factors for peripheral neuropathy and vasculopathy were determined by univariate and multivariate logistic regression analysis. Statistical significance was considered with $\mathrm{P}$ value of $<0.05$. Result: Fifty seven patients $(37.7 \%)$ had early neuropathy with MNSI score of $3.3 \pm 0.4$. Thirty seven patients (20.6\%) had vasculopathy with $\mathrm{ABI}$ score of $0.76 \pm 0.11$. Age (Odd ratio 1.07 (1.02 - 1.11), p 0.003), duration of symptoms (Odd ratio 1.11 95\% CI: $1.05-1.17, \mathrm{p} \leq$ 0.001), high HbA1C \% (Odd ratio 1.94 95\% CI: $1.54-2.45$, P $\leq 0.001$ ), albumin creatinine ratio (Odd ratio 1.01, 95\% CI: $1.00-1.01, \mathrm{P} \leq 0.001$ ) and cholesterol level (Odd ratio 1.01 95\% CI: $1.01-1.02, \mathrm{p}=0.001$ ) were found as risk factors for early neuropathy and vasculopathy. Conclusion: Peripheral neuropathy and vasculopathy are frequently reported complications among newly diagnosed treatment naïve patients of type $2 \mathrm{DM}$. Age, duration of symptoms prior to diagnosis, metabolic parameters like raised $\mathrm{HbA1C}$, hyperlipidemia and spot random albumin creatinine ratio are found to be risk factors for both peripheral neuropathy and vasculopathy.
\end{abstract}




\section{Keywords}

Peripheral Neuropathy, Peripheral Vasculopathy, Type 2 Diabetes Mellitus

\section{Introduction}

The increasing global prevalence of diabetes has been estimated about 8.5\% [1]. Prevalence of diabetes has more rising trend in middle- and low-income countries as reported by World Health Organization. Diabetes has been connected to the major cause of renal failure, blindness, myocardial infarction, stroke and lower limb amputation. In 2030 diabetes will be the 7th leading cause of death as predicted by World Health Organization [2]. The prevalence of diabetes in Pakistan is $11.47 \%$ [3]. The reported prevalence of diabetic foot ulceration in Pakistan is between 4 and 10\%, with the amputation rate of $8 \%-21 \%$ [4] [5]. How much amputation contributes in the overall mortality in Pakistan is not known.

Foot problems related to diabetes are a well known complication where approximately $5 \%$ of patients may require major amputation. Diabetic foot ulcers have been observed in nearly $25 \%$ of patients during their course of illness [6] [7]. Peripheral neuropathy, vasculopathy, and immunopathy are the main underlying mechanism for diabetic foot complications [8] [9]. Peripheral diabetic neuropathy affects sensory, motor and autonomic components and collectively triggers diabetic foot ulcers [10] [11]. Hyperglycemia induced damage to nerve fibers in both lateral spinothalamic and posterior column contributes to foot ulceration. The reported global prevalence of peripheral neuropathy in diabetes is $30 \%-50 \%$. Peripheral neuropathy is considered as a main cause $(>60 \%)$ of diabetic foot ulcers [8].

Apart from neuropathy, the role of diabetic vasculopathy in diabetic foot complications cannot be undermined. Peripheral arterial disease (PAD) is an important risk factor associated with complication related to diabetic foot; poor wound healing, impaired perfusion, deformity and superimposed infections [9]. Peripheral arterial occlusive disease at the bifurcation of abdominal aorta is common among old people [12]. Vasculopathy remains undetected as initially most of the patients are asymptomatic with ankle brachial index $<0.9$. Hyperglycemia induced Microvascular complications and loss of demyelinated nerve fibers are possible underlying mechanisms for neurovasculopathy [10] [13]. There are various risk factors associated with diabetic foot like duration of disease, age, gender and poor glycemic control. Foot problems related to diabetes are a common reason for hospitalization which leads to lower limb amputation. It poses a great challenge both in terms of economic and quality of life among patients [14]. Earlier data has shown increase mortality among diabetics from 30\% - 70\% after lower limb amputation [15] [16] [17].

Pakistan being a poor country with socioeconomic constrains having improper primary health care system has a high burden of diseases where diabetes and 
its complications cause severe impact on health economics thus magnifying the importance of reaching out to the suffering families having been long ignored on this subject like many others. This epitaph alone has enough reason for paying importance to family medicine in this part of the world. The prevalence of diabetes in Pakistan is $11.45 \%$ [3]. The reported prevalence of diabetic foot ulceration in Pakistan is between 4 and $10 \%$, with the amputation rate of $8 \%-21 \%$ [4] [5]. Early detection or screening of peripheral neuropathy and vasculopathy with timely intervention or institution of their treatment among diabetics will definitely reduce diabetic foot ulcers and eventually the frequency of amputations. It also aids to strategize comprehensive foot care programme to minimize rate of amputation and eventually mortality. The study is aimed to determine the frequency of early diabetic neuropathy and vasculopathy among patients attending tertiary care public hospital. The study further aims to determine the risk factors associated with peripheral neuropathy and vasculopathy.

\section{Methodology}

Prior to the commencement of research the approval was taken from the Institutional review board (IRB). It was a cross sectional non interventional cohort study where all diabetic patients attending Medical OPD of medical unit 1, CHK and DUHS from November 2017 to January 2018 were enrolled. A sample of 155 diabetic will be included considering $11.5 \%$ prevalence [3] of diabetes in Pakistan.

\subsection{Research Participant}

All cases of newly diagnosed treatment naïve T2DM with age $\geq 20$ years to 60 years were enrolled. T2DM was diagnosed in accordance to ADA criteria where any of the following criteria met as FPG $\geq 126 \mathrm{mg} / \mathrm{dL}(7.0 \mathrm{mmol} / \mathrm{L})$ or $2-\mathrm{h} \mathrm{PG} \geq$ $200 \mathrm{mg} / \mathrm{dL}(11.1 \mathrm{mmol} / \mathrm{L})$ during OGTT or A1C $\geq 6.5 \%(48 \mathrm{mmol} / \mathrm{mol})$ or a patient with classic symptoms of hyperglycemia or hyperglycemic crisis, a random plasma glucose $\geq 200 \mathrm{mg} / \mathrm{dL}$ (11.1 mmol/L). Patients with type $1 \mathrm{DM}$ along with patients who already have serious diabetic complications like lower limb amputation were excluded. Patients with any symptoms suggesting nephropathy as well as known smokers will also be excluded.

\subsection{Research Instruments}

\subsubsection{Demographic Profile}

All demographic details of patients like age, gender, marital status, and duration of diabetes, any previous screening for neuropathy, and previous history of foot ulcer and history of any comorbids were recorded through specially designed proforma.

\subsubsection{Peripheral Diabetic Neuropathy}

Diabetic neuropathy was measured by the Michigan neuropathy screening instrument (MNSI) a reliable and validated tool for this purpose where a total score of 0 - 10 was obtained [18] [19]. Vibration sensations were determined on 
the dorsum of the big toe by a turning fork $(128-\mathrm{Hz})$ which could help to determine even early neuropathy [20]. Each participant feet was assessed by MNSI scoring for five defined parameters which includes appearance, ulceration, vibration sensations, ankle jerk and touch pressure modality of sensation. Each above parameter has 0.1 and 1.5 points. Peripheral neuropathy was confirmed or diagnosed when patient on a 10-point scale has MNSI score of $\geq 2.5$.

\subsubsection{Peripheral Vasculopathy}

Vascular status of extremity was determined by ankle brachial index (ABI). Peripheral vasculopathy was labeled when $\mathrm{ABI}$ values of $\leq 0.89$ against 0.9 of normal [15].

\subsubsection{Metabolic Indicators}

Fasting blood sugar (FBS), lipid profile and creatinine is determined by Auto analyzer. Glycated haemoglobin $\left(\mathrm{HbA}_{1} \mathrm{C}\right.$ determined by high performance liquid chromatography (HPLC), urinary albumin was determined by a radioimmunoassay technique (Immunotech, Prague, Czech Republic). Spot urinary albumin creatinine ratios (ACR) were calculated for all patients.

\subsubsection{Statistical Analysis}

The data of the study will be analyzed through SPSS version 21 where Data was conveyed as mean $\pm \mathrm{SD}$ and respective frequencies. Data was evaluated by Student's t-test and $\chi^{2}$ analyses for proportions and continuous variables, respectively. Risk factors for peripheral neuropathy and vasculopathy were determined by multivariate logistic regression analyses. Statistical significance was considered with $\mathrm{P}$ value of $<0.05$.

\section{Results}

\subsection{Demographic Profiles}

Demographic profiles along with clinical details of patients are shown in Table 1. Male gender predominates $58 \%$ in this study. Patients had mean age of 49.6 (8.5 \pm ) years with 8.0 (IQR 38) months duration of symptoms related to diabetes prior to diagnosis. Metabolic indicators at presentation are as median serum cholesterol of $185 \mathrm{mg} / \mathrm{dL}$ (IQR 171), median random spot urinary albumin to creatinine ratio (ACR) 192 (IQR 492) $\mu \mathrm{g} / \mathrm{mg}$ and median HbAlC of 8 (IQR 8).

\subsection{Peripheral Neuropathy}

MNSI score was calculated in all patients and patients were segregated with and without neuropathy on the basis of MNSI score. 57 patients (37.7\%) had early neuropathy with MNSI score of $3.3 \pm 0.4$ whereas 98 (63.3\%) patients had no neuropathy with MNSI score of $1.2 \pm 0.7$ as shown in Table 2 .

\subsection{Peripheral Vasculopathy}

$\mathrm{ABI}$ was determined in all patients where patients were divided into vasculopathy 
Table 1. Demographic profile of patients.

\begin{tabular}{cc}
\hline Characteristics & Statistics (N = 155) \\
\hline Mean age in years (SD) & $49.6(8.5)$ \\
Gender, n males (\%) & $90(58.1)$ \\
Duration of symptoms in months, Median (IQR) & $8(10)$ \\
Total cholesterol level in mg/dL, Median (IQR) & $185(83)$ \\
HbA1C level (\%), Median (IQR) & $8.3(3.2)$ \\
Albumin to Creatinine ratio in $\mu$ g/mg, Median (IQR) & $192(231)$ \\
MNSI score for early neuropathy, Median (IQR) & $2.0(2.0)$ \\
ABI score for early vasculopathy, Median (IQR) & $1.0(0.2)$ \\
\hline
\end{tabular}

MNSI (Michigan neuropathy screening instrument); ABI (Ankle brachial index); IQR (inter quartile range).

Table 2. Demographic characteristics of patients with and without early neuropathy and vasculopathy.

\begin{tabular}{|c|c|c|c|}
\hline Characteristics & $\begin{array}{l}\text { Patients with Peripheral } \\
\text { neuropathy and } \\
\text { vasculopathy }(n=89)\end{array}$ & $\begin{array}{c}\text { Patients without Peripheral } \\
\text { neuropathy and } \\
\text { vasculopathy }(n=66)\end{array}$ & $P$ value ${ }^{\gamma}$ \\
\hline Mean age in years (SD) & $51.4(8.6)$ & $47.2(7.6)$ & 0.002 \\
\hline Gender, $\mathrm{n}$ males (\%) & $53(59.6)$ & $37(56.1)$ & 0.66 \\
\hline $\begin{array}{l}\text { Duration of symptoms in } \\
\text { months, Median (IQR) }\end{array}$ & $10(14)$ & $7(7)$ & 0.012 \\
\hline $\begin{array}{l}\text { Total cholesterol level in } \\
\text { mg/dL, Median (IQR) }\end{array}$ & $189(82)$ & $174(87)$ & 0.001 \\
\hline $\begin{array}{l}\text { HBA1C level (\%), Median } \\
\text { (IQR) }\end{array}$ & $9.3(2.4)$ & $7.0(2.4)$ & $<0.001$ \\
\hline $\begin{array}{l}\text { Albumin to Creatinine ratio } \\
\text { in } \mu \mathrm{g} / \mathrm{mg} \text {, Median (IQR) }\end{array}$ & $255(197)$ & $97(186)$ & $<0.001$ \\
\hline $\begin{array}{c}\text { MNSI score for early } \\
\text { neuropathy, Median (IQR) }\end{array}$ & $3.0(1.0)$ & $1.0(1.0)$ & $<0.001$ \\
\hline $\begin{array}{c}\text { ABI score for early } \\
\text { vasculopathy, Median (IQR) }\end{array}$ & $0.9(0.2)$ & $1.1(0.1)$ & $<0.001^{*}$ \\
\hline
\end{tabular}

versus no vasculopathy. 32 patients (20.6\%) had vasculopathy with $A B I$ score of $0.76 \pm 0.11$ whereas $123(79.4 \%)$ patients had no peripheral vasculopathy with ABI score of $1.05 \pm 0.08$ as shown in Table 2 .

\subsection{Albumin Creatinine Ratio (ACR)}

ACR was determined among all patients with and without neuropathy and vasculopathy. Patients with detected neuropathy and vasculopathy had ACR of 255 $(\mu \mathrm{g} / \mathrm{mg})$ with median of $197(\mu \mathrm{g} / \mathrm{mg})$ whereas ACR of $97(\mu \mathrm{g} / \mathrm{mg})$ with median of $186(\mu \mathrm{g} / \mathrm{mg})$ was found in patients without peripheral neuropathy and vasculopathy.

\subsection{Associations of Early Neuropathy and Vasculopathy}

Various demographic and metabolic parameters were compared among patients 
with and without early neuropathy and vasculopathy as shown in Table 2 . Increasing age $(\mathrm{p}=0.002)$, duration of symptoms $(\mathrm{p}=0.012)$ among demographic parameters had significant associations amongst patients with and without early neuropathy and vasculopathy. MNSI score for peripheral neuropathy ( $\mathrm{p} \leq 0.001$ ) and ABI score for peripheral vasculopathy $(\mathrm{p}<0.001)$ were also found to be significant in patients with and without peripheral neuropathy and vasculopathy. Among metabolic parameters, high HbA1C \% ( $\mathrm{p} \leq 0.001)$, ACR $(\mathrm{P} \leq 0.001)$ and high cholesterol $(\mathrm{p}=0.00)$ had shown significant association between patients with and without peripheral neuropathy and vasculopathy.

\subsection{Risk Factors for Early Neuropathy and Vasculopathy}

All significant associations among patients with and without peripheral neuropathy and vasculopathy were assessed for risk factors by applying univariate logistic regression analysis. Age (Odd ratio 1.07 (1.02 - 1.11), $\mathrm{p}=0.003$ ), duration of symptoms (Odd ratio $1.1195 \% \mathrm{CI}: 1.05-1.17, \mathrm{p} \leq 0.001$ ), high HbA1C \% (Odd ratio 1.94 95\% CI: $1.54-2.45, \mathrm{P} \leq 0.001$ ), ACR (Odd ratio 1.01, 95\% CI: $1.00-1.01, \mathrm{P}<0.001$ ) and cholesterol level (Odd ratio 1.01 95\% CI: 1.01 - 1.02, $\mathrm{p}=0.001$ ) were all found to be risk factors for peripheral neuropathy and vasculopathy among newly diagnosed treatment naïve patients as shown in Table 3. Increasing age (Odd ratio 1.08, 95\% CI: $1.02-1.14, \mathrm{P}=0.012$ ), duration of symptoms (Odd ratio 1.10, 95\% CI: 1.02 - 1.19, P = 0.01), high HbA1C \% (Odd ratio 4.32, 95\% CI: $2.44-7.66, \mathrm{p} \leq 0.001$ ), ACR (Odd ratio 1.01, 95\% CI: 1.00 $1.01, \mathrm{P}=0.004)$ were also found to be independent risk factors for both peripheral neuropathy and vasculopathy as shown in Table 4.

Table 3. Risk factors for early diabetic peripheral neuropathy and vasculopathy.

\begin{tabular}{ccc}
\hline Variables & Odds Ratio $(\mathbf{9 5 \%} \mathrm{CI})$ & P-value \\
\hline Age & $1.07(1.02-1.11)$ & 0.003 \\
Gender & $1.15(0.61-2.20)$ & 0.663 \\
Duration of symptoms & $1.11(1.05-1.17)$ & $<0.001$ \\
Total cholesterol level & $1.01(1.01-1.02)$ & 0.001 \\
HBA1C level & $1.94(1.54-2.45)$ & $<0.001$ \\
Albumin to creatinine ratio & $1.01(1.00-1.01)$ & $<0.001$ \\
\hline
\end{tabular}

Table 4. Multivariate logistic regression analyses of variables associated with Peripheral neuropathy and vasculopathy.

\begin{tabular}{ccc}
\hline Variables & Odds Ratio (95\% CI) & P-value \\
\hline Age & $1.08(1.02-1.14)$ & 0.012 \\
Duration of symptoms & $1.10(1.02-1.19)$ & 0.01 \\
Total cholesterol level & $0.96(0.94-0.98)$ & $<0.001$ \\
HBA1C level & $4.32(2.44-7.66)$ & $<0.001$ \\
Albumin to creatinine ratio & $1.01(1.00-1.01)$ & 0.004 \\
\hline
\end{tabular}




\section{Discussion}

The current study determined frequency of peripheral neuropathy and vasculopathy among newly diagnosed treatment naïve patients of type $2 \mathrm{DM}$ along with associated risk factors. Male gender (58\%) predominates in this study which is similar to earlier studies [21] [22]. Mean age of patients were 49.6 (8.5 \pm ) which is again in agreement to earlier study where mean ages were $51.3 \pm 12.3$ and $52.39 \pm 10.03$ years respectively [21] [22]. Patients in this study had 8 months (median $10 \mathrm{IQR}$ ) duration of symptoms prior to diagnosis of DM which is in accordance to reported data of Gill HK et al. [21] where duration of symptoms was $8.4 \pm 9.9$ months.

Peripheral neuropathy was detected in 57 patients (37.7\%) with MNSI score of $3.3 \pm 0.4$ in newly diagnosed type 2 patients of DM with cut off score $\geq 2.5$. Lee et al. [23] in their study found $34.5 \%$ peripheral neuropathy detected by same MNSI instrument with same cut off $\geq 2.5$. Chen et al. [13] has shown $22.5 \%$ peripheral neuropathy however they used MNSI score cut off $>3$. A European study [24] has shown higher frequency (43.5\%) of peripheral neuropathy compare to this study. A large cross sectional study [22] of 2000 newly diagnosed type 2 diabetics has shown peripheral neuropathy of $52 \%$ but it was detected by neuropathy disability score (NDS) rather than MNSI. Vasculopathy was found in $(20.6 \%)$ of patients with ABI score of $0.76 \pm 0.11$ in this current study. Lee et al. [23] has also shown $17.5 \%$ of peripheral vasculopathy in newly diagnosed type 2 patients. The earlier reported prevalence of peripheral vasculopathy among type 2 diabetic patient in Asia (20\%), Taiwan (17.7\%) and United States (20\%) [25] [26].

Several risk factors like age, bad glycemic control, gender, prolong duration of diabetes, hypertension, retinopathy, smoking, and alcohol consumption were previously determined for peripheral neuropathy among type 2 newly diagnosed DM [27] [28] [29] [30]. In current study, age at diagnosis and duration of symptoms prior to diagnosis were found to be significant risk factors for peripheral neuropathy and vasculopathy. Earlier studies [31] [32] on the subject have also shown similar findings. Previously Smith AG et al. and Dyck PJ et al. [33] [34] did not find the similar results and contrasted our study.

The current study has shown significant association of hyperlipidemia where it is found to be a risk factor for peripheral neuropathy when compared between patients with and without peripheral neuropathy. Hyperlipidemia is not only found to be a risk factor but early dyslipidemia among type 2 diabetics has shown a main independent risk factor for the development of diabetic peripheral neuropathy as evidenced from emerging data of various large scale trials [35] [36] [37]. An earlier study also supported this current study and showed that obesity and hypertriglyceridemia is a risk factor for early peripheral neuropathy independent to glucose control [38].

The current study has shown high $\mathrm{HbA1C}$ as a risk factor for peripheral neuropathy with odds of 4.32, 95\% CI: 2.44 - 7.66 when compared among groups 
with and without peripheral neuropathy. Previous study [39] has shown similar results where high levels of glycated haemoglobin were found to be a risk factor for peripheral neuropathy. A large recent study [40] has shown high HbA1C as an early marker of peripheral neuropathy among type 2 diabetics. The above referred study determined both the coefficient of variability of $\mathrm{HbA1C}$ and mean $\mathrm{HbA1C}$ in their patients. A previous study [21] contrasted to this current study and did not confirm high $\mathrm{HbA1C}$ as a risk factor for peripheral neuropathy.

ACR with odds of $(1.01,95 \%$ CI: 1.00 - 1.01) were found to be a risk factor for peripheral neuropathy in this study when compared between patients with and without peripheral neuropathy and vasculopathy. Earlier study [21] has shown prevalence of albuminuria of $7.9 \%$ but did not find it as a risk factor for peripheral neuropathy. Spijkerman AM et al. and Shaw JE et al. [29] [41] have shown variable association between peripheral neuropathy and albuminuria.

Peripheral vasculopathy in this study has also shown significant association with various parameters like age, duration of symptoms prior to diagnosis as discussed earlier. High $\mathrm{HbA1C}$ levels are found to risk factor for peripheral vasculopathy among type 2 diabetic in this study. Lee CM et al. [23] has shown raised $\mathrm{HbA1C}$ as a risk factor for peripheral vasculopathy in newly diagnosed type 2 DM. Hyperlipidemia was found to be significantly associated as a risk factor for peripheral vasculopathy in this study. Solanki et al. [42] has shown significant association between hyperlipidemia with peripheral vasculopathy which is in agreement with our study. ACR (Odd ratio 1.01, 95\% CI: 1.00 - 1.01, $\mathrm{P}=0.004)$ found to risk factors for peripheral vasculopathy in this study. Wattanakit $\mathrm{K}$ et al. [43] in their study concluded that presence but not the quantification of albuminuria, is an important risk factor for peripheral vasculopathy in diabetics. The above referred study is in agreement with our study.

By multivariate logistic regression applied to risk factor for peripheral neuropathy and vasculopathy in this study has shown duration of symptoms prior to diagnosis, age, raised $\mathrm{HbA1C}, \mathrm{ACR}$ and hyperlipidemia were found to be independent factors for neuropathy and vasculopathy. Earlier study [21] has also shown duration of symptoms and age to be an independent risk factor.

There are certain limitations of this study as neuropathy and vasculopathy group should have been compared with healthy control which would have further strengthen the study. The peripheral neuropathy was not confirmed by nerve conduction studies.

\section{Conclusion}

Peripheral neuropathy and vasculopathy are frequently detected complications among newly diagnosed treatment naïve patients of type $2 \mathrm{DM}$. Age, duration of symptoms prior to diagnosis, metabolic parameters like raised HbA1C, hyperlipidemia and spot random albumin creatinine ratio are found to be risk factors for both peripheral neuropathy and vasculopathy. The study recommends early detection of peripheral neuropathy and vasculopathy is of paramount impor- 
tance as its timely intervention or institution of their treatment among diabetics will definitely reduce diabetic foot ulcers and eventually the frequency of amputations.

\section{Conflicts of Interest}

The authors declare no conflicts of interest regarding the publication of this paper.

\section{References}

[1] Global Report on Diabetes. World Health Organization, Geneva, 2016. http://www.who.int/diabetes/global-report/en/

[2] Mathers, C.D. and Loncar, D. (2006) Projections of Global Mortality and Burden of Disease from 2002 to 2030. PLoS Medicine, 3, e442. https://doi.org/10.1371/journal.pmed.0030442

[3] Nishtar, S. and Shera, S. (2006) Diabetes Prevention and Control as a Part of an Integrated Non-Communicable Disease Strategy: The Pakistan Approach. Practical Diabetes International, 23, 332-334. https://doi.org/10.1002/pdi.999

[4] Ali, S.M., Basit, A., Sheikh, T., Mumtaz, S. and Hydrie, M.Z. (2001) Diabetic Foot Ulcer-A Prospective Study. Journal of Pakistan Medical Association, 51, 78-81.

[5] Ince, P., Abbas, Z.G., Lutale, J.K., et al. (2008) Use of the SINBAD Classification System and Score in Comparing Outcome of Foot Ulcer Management on Three Continents. Diabetes Care, 31, 964-967. https://doi.org/10.2337/dc07-2367

[6] Lipsky, B.A., Berendt, A.R., Deery, H.G., Embil, J.M., Joseph, W.S. and Karchmer, A.W. (2006) Diagnosis and Treatment of Diabetic Foot Infections. Plastic and Reconstructive Surgery, 117, 212S-238S. https://doi.org/10.1097/01.prs.0000222737.09322.77

[7] Zgonis, T., Stapleton, J.J., Girard-Powell, V.A. and Hagino, R.T. (2008) Surgical Management of Diabetic Foot Infections and Amputations. AORN Journal, 87, 935-950. https://doi.org/10.1016/j.aorn.2008.02.014

[8] Bowering, C.K. (2001) Diabetic Foot Ulcers: Pathophysiology, Assessment, and Therapy. Canadian Family Physician, 47, 1007-1016.

[9] Li, C.M., Chang, C.C., Chen, C.M., Lai, L.J. and Chen, M.Y. (2013) The Devil Is in the Detail: Prevention of Diabetic Foot Ulceration in Rural Areas Is Possible. Open Journal of Nursing, 3, 257-264. https://doi.org/10.4236/ojn.2013.32035

[10] Fard, A.S., Esmaelzadeh, M. and Larijani, B. (2007) Assessment and Treatment of Diabetic Foot Ulcer. International Journal of Clinical Practice, 61, 1931-1938. https://doi.org/10.1111/j.1742-1241.2007.01534.x

[11] Faglia, E., Clerici, G., Clerissi, J., Gabrielli, L., Losa, S. and Mantero, M. (2009) Long-Term Prognosis of Diabetic Patients with Critical Limb Ischemia: A Population-Based Cohort Study. Diabetes Care, 32, 822-827. https://doi.org/10.2337/dc08-1223

[12] Alzamora, M.T., Forés, R., Baena-Díez, J.M., Pera, G., Toran, P. and Sorribes, M. (2010) The Peripheral Arterial Disease Study: Prevalence and Risk Factors in the General Population. BMC Public Health, 10, 38-48. https://doi.org/10.1186/1471-2458-10-38

[13] Chen, M.Y., Huang, W.C., Peng, Y.S., Guo, J.S., Chen, C.P. and Jong, M.C. (2011) Effectiveness of a Health Promotion Programme for Farmers and Fishermen with Type-2 Diabetes in Taiwan. Leading Global Nursing Research, 67, 2060-2067. 
https://doi.org/10.1111/j.1365-2648.2011.05678.x

[14] World Health Organization, WHO: Diabetes. 2014. http://www.who.int/mediacentre/factsheets/fs312/en/index.html

[15] American Diabetes Association, ADA (2011) Clinical Practice Recommendations. Diabetes Care, 34, S11-S61.

[16] Gordois, A., Scuffham, P., Shearer, A., Oglesby, A. and Tobian, J.A. (2003) The Health Care Costs of Diabetic Peripheral Neuropathy in the U.S. Diabetes Care, 26, 1790-1795. https://doi.org/10.2337/diacare.26.6.1790

[17] Williams, D.T., Harding, K.G. and Price, P. (2005) An Evaluation of the Efficacy of Methods Used in Screening for Lower-Limb Arterial Disease in Diabetes. Diabetes Care, 28, 2206-2210. https://doi.org/10.2337/diacare.28.9.2206

[18] Chang, C.H., Peng, Y.S., Chang, C.C. and Chen, M.Y. (2013) Useful Screening Tools for Preventing Foot Problems of Diabetics in Rural Areas: A Cross-Sectional Study. BMC Public Health, 13, 612. https://doi.org/10.1186/1471-2458-13-612

[19] Moghtaderi, A., Bakhshipour, A. and Rashidi, H. (2006) Validation of Michigan Neuropathy Screening Instrument for Diabetic Peripheral Neuropathy. Clinical Neurology and Neurosurgery, 108, 477-481. https://doi.org/10.1016/j.clineuro.2005.08.003

[20] Feng, Y., Schlösser, F.J. and Sumpio, B.E. (2009) The Semmes Weinstein Monofilament Examination as a Screening Tool for Diabetic Peripheral Neuropathy. Journal of Vascular Surgery, 50, 675. https://doi.org/10.1016/j.jvs.2009.05.017

[21] Gill, H.K., Yadav, S.B., Ramesh, V. and Bhatia, E. (2014) A Prospective Study of Prevalence and Association of Peripheral Neuropathy in Indian Patients with Newly Diagnosed Type 2 Diabetes Mellitus. Journal of Postgraduate Medicine, 60, 270-275. https://doi.org/10.4103/0022-3859.138750

[22] Heydari, I., Radi, V., Razmjou, S. and Afsaneh, A. (2010) Chronic Complications of Diabetes Mellitus in Newly Diagnosed Patients. International Journal of Diabetes Mellitus, 2, 61-63. https://doi.org/10.1016/j.ijdm.2009.08.001

[23] Lee, C.M., Chang, C.C., Pan, M.Y., Chang, C.F. and Chen, M.Y. (2014) Insufficient Early Detection of Peripheral Neurovasculopathy and Associated Factors in Rural Diabetes Residents of Taiwan: A Cross-Sectional Study. BMC Endocrine Disorders, 14, 89. https://doi.org/10.1186/1472-6823-14-89

[24] Geerts, M., Bours, G.J.J., de Wit, R., Landewe, S.A.N., van Haarlem, A. and Schaper, N.C. (2009) Prevalence and Impact of Pain in Diabetic Neuropathy. European Diabetes Nursing, 6, 58-64. https://doi.org/10.1002/edn.136

[25] Rhee, S.Y., Guan, H., Liu, Z.M., Cheng, S.W., Waspadji, S. and Palmes, P. (2007) Multi-Country Study on the Prevalence and Clinical Features of Peripheral Arterial Disease in Asian Type 2 Diabetes Patients at High Risk of Atherosclerosis. Diabetes Research and Clinical Practice, 76, 82-92. https://doi.org/10.1016/j.diabres.2006.07.029

[26] Tseng, C.H. (2003) Prevalence and Risk Factors of Peripheral Arterial Obstructive Disease in Taiwanese Type 2 Diabetic Patients. Angiology, 54, 331-338. https://doi.org/10.1177/000331970305400309

[27] Ratzmann, K.P., Raschke, M., Gander, I. and Schimke, E. (1991) Prevalence of Peripheral and Autonomic Neuropathy in Newly Diagnosed Type II (Noninsulin-Dependent) Diabetes. Journal of Diabetes and Its Complications, 5, 1-5. https://doi.org/10.1016/0891-6632(91)90002-7

[28] Weerasuriya, N., Siribaddana, S., Dissanayake, A., Subasinghe, Z., Wariyapola, D. 
and Fernando, D.J. (1998) Long-Term Complications in Newly Diagnosed Sri Lankan Patients with Type 2 Diabetes Mellitus. QJM, 91, 439-443. https://doi.org/10.1093/qjmed/91.6.439

[29] Spijkerman, A.M., Dekker, J.M., Nijpels, G., Adriaanse, M.C., Kostense, P.J., Ruwaard, D., et al. (2003) Microvascular Complications at Time of Diagnosis of Type 2 Diabetes Are Similar among Diabetic Patients Detected by Targeted Screening and Patients Newly Diagnosed in General Practice: The Hoorn Screening Study. Diabetes Care, 26, 2604-2608. https://doi.org/10.2337/diacare.26.9.2604

[30] Pradeepa, R., Rema, M., Vignesh, J., Deepa, M., Deepa, R. and Mohan, V. (2008) Prevalence and Risk Factors for Diabetic Neuropathy in an Urban South Indian Population: The Chennai Urban Rural Epidemiology Study (CURES-55). Diabetic Medicine, 25, 407-412. https://doi.org/10.1111/j.1464-5491.2008.02397.x

[31] Novella, S.P., Inzucchi, S.E. and Goldstein, J.M. (2001) The Frequency of Undiagnosed Diabetes and Impaired Glucose Tolerance in Patients with Idiopathic Sensory Neuropathy. Muscle Nerve, 24, 1229-1231. https://doi.org/10.1002/mus.1137

[32] Singleton, J.R., Smith, A.G. and Bromberg, M.B. (2001) Increased Prevalence of Impaired Glucose Tolerance in Patients with Painful Sensory Neuropathy. Diabetes Care, 24, 1448-1453. https://doi.org/10.2337/diacare.24.8.1448

[33] Smith, A.G., Ramachandran, P., Tripp, S. and Singleton, J.R. (2001) Epidermal Nerve Innervations in Impaired Glucose Tolderance and Diabetes-Associated Neuropathy. Neurology, 57, 1701-1704. https://doi.org/10.1212/WNL.57.9.1701

[34] Dyck, P.J., Clark, V.M., Overland, C.J., Davies, J.L., Pach, J.M., Dyck, P.J., et al. (2012) Impaired Glycemia and Diabetic Polyneuropathy: The OC IG Survey. Diabetes Care, 35, 584-591. https://doi.org/10.2337/dc11-1421

[35] Cameron, N., Cotter, M., Inkster, M. and Nangle, M. (2003) Looking to the Future: Diabetic Neuropathy and Effects of Rosuvastatin on Neurovascular Function in Diabetes Models. Diabetes Research and Clinical Practice, 61, S35-S39. https://doi.org/10.1016/S0168-8227(03)00123-2

[36] Gordon, S.A. and Robinson, S.J. (2006) Idiopathic Neuropathy, Prediabetes and the Metabolic Syndrome. Journal of the Neurological Sciences, 242, 9-14. https://doi.org/10.1016/j.jns.2005.11.020

[37] Leiter, L.A. (2005) The Prevention of Diabetic Microvascular Complications of Diabetes: Is There a Role for Lipid Lowering? Diabetes Research and Clinical Practice, 68, S3-S14. https://doi.org/10.1016/j.diabres.2005.03.015

[38] Gordon, S.A. and Robinson, S.J. (2013) Obesity and Hyperlipidemia Are Risk Factors for Early Diabetic Neuropathy. Journal of Diabetic Complications, 27, 436-442. https://doi.org/10.1016/j.jdiacomp.2013.04.003

[39] Wang, N., Guo, C., Han, P. and Li, T. (2016) Glycated Albumin Indicates Peripheral Diabetic Neuropathy. Acta Diabetologica, 53, 973-979. https://doi.org/10.1007/s00592-016-0900-y

[40] Su, J.B., Zhao, L.H., Zhang, X.L., Cai, H.L., Huang, H.Y., Xu, F., Chen, T. and Wang, X.Q. (2018) HbA1c Variability and Diabetic Peripheral Neuropathy in Type 2 Diabetic Patients. Cardiovascular Diabetology, 17, 47.

[41] Shaw, J.E., Hodge, A.M., de Courten, M., Dowse, G.K., Gareeboo, H., Tuomilehto, J., et al. (1998) Diabetic Neuropathy in Mauritius: Prevalence and Risk Factors. Diabetes Research and Clinical Practice, 42, 131-139. https://doi.org/10.1016/S0168-8227(98)00100-4

[42] Solanki, J.D., Gokhale, P.A., Makwana, A.H., Mehta, H. and Shah, C. (2013) A 
Study of Prevalence and Association of Risk Factors for Diabetic Vasculopathy in an Urban Area of Gujarat. Journal of Family Medicine and Primary Care, 2, 360. https://doi.org/10.4103/2249-4863.123906

[43] Wattanakit, K., Folsom, A.R., Criqui, M.H., Kramer, H.J., Cushman, M., Shea, S. and Hirsch, A.T. (2008) Albuminuria and Peripheral Arterial Disease: Results from the Multi-Ethnic Study of Atherosclerosis (MESA). Atherosclerosis, 201, 212-216. https://doi.org/10.1016/j.atherosclerosis.2007.12.044 